\title{
Ozone utilisation in decreasing water sources load with resistant and toxic substances
}

\author{
Michal Melicher, Ján Derco, Lenka Sumegová, Miloslav Drtil \\ Faculty of Chemical and Food Technology, Slovak University of Technology, \\ Institute of Chemical and Environmental Engineering, Radlinského 9, 81237 Bratislava, Slovakia \\ jan.derco@stuba.sk
}

\begin{abstract}
Water is becoming a strategic raw material and thus, protection of water resources belongs to priorities. Toxic substances need to be removed prior to the biological treatment stage in a WWTP. Biologically resistant substances flow through the biological treatment stage in a WWTP directly to water recipients, and can travel as far as to the underground water and drinking water sources. Taking into account the large volumes of these substances, their removal from ground water and water sources would be extremely costly. It is economical therefore to remove these already at their source or in a WWTP using separation or degradation processes. This paper deals with the possibility to use ozonisation for pretreatment of wastewater prior to the WWTP biological stage. Benzothiazole removal efficiency exceeding $95 \%$ within $60 \mathrm{~min}$. of ozonation was reached when combining ozonation with zeolite addition. Partially oxidised COD portion was significant in the first 15 minutes, followed by subsequent growth of mineralised COD portion.
\end{abstract}

Keywords: benzothiazole, biologically resistant pollutants, kinetics, ozonation, toxicity, water protection, zeolite

\section{Introduction}

The ever stricter EU requirements for discharged wastewater quality (WFD 2000/60/EC) have to be followed by stricter monitoring of their content in priority hazardous and priority substances.

More strict requirements for discharged wastewater quality (Directive 2000/60/EC) follow from the Environmental Quality Standards (EQS) for priority and priority hazardous substances (Directive 2008/105/EC).

For Slovakia, 59 relevant substances were defined for discharged wastewater and water environment. The priority is to remove these in a wastewater treatment plant (WWTP) while their concentration is relatively high, preventing thus their transfer into recipients and subsequently to water sources, where their removal would be very costly due to their large volumes.

Benzothiazole (BT), mercaptobenzothiazole (2MBT) transformation product, is classified among these substances as a strong contact allergen soluble in solutions of salts like the human sweat and causing dermatitis. 2-MBT also causes tumour diseases (Gold et al., 1984). It is a toxic substance highly resistant to biological treatment (Chudoba et al., 1977) and belongs to xenobiotic and persistent substances mainly used in the rubber processing industry as a vulcanisation accelerator, and also as a herbicide, fungicide and corrosion inhibition agent in cooling systems (de Wever and Verachtert, 1997).
Biological treatment processes performed in a WWTP cannot decompose all benzothiazolederivates. According to Klopfer et al. (2004), concentrations of BT, 2-MBT and hydroxybenzothiazole decrease, however that of benzothiazole acids and 2-methyltiobenzothiazole increase.

Ozone oxidation is one of the potential processes for the removal of benzothiazole derivates. Ozone oxidation is suitable for the removal of aromatic substances and thus considered as a potential benzothiazole derivates removal process. Increased efficiency in organic pollutants removal was also observed in ozonation combined with absorption materials, e.g. adsorptive ozonation (Fujita et al., 2004) or catalytic ozonation (Valdés et al., 2008; 2009). Zeolites are suitable for ozonation with heterogeneous adsorbents, as these are cheap and easily available natural materials.

This study deals with the potential use of combined ozonation processes for wastewater pre-treatment prior to its biological treatment stage in a WWTP. Also, the possible adaptation of activated sludge to benzothiazolederivates was tested.

\section{Materials and methods}

A mechanically stirred reactor (Fig. 1) was used for ozonation combined with zeolites $\left(\mathrm{O}_{3} / \mathrm{ZEO}\right)$ (grain size ranged from $\mathrm{d}=0.315 \mathrm{~mm}$ up to $0.4 \mathrm{~mm}$ ). The total reactor volume was $200 \mathrm{ml}$, while $100 \mathrm{ml}$ thereof was the efficient volume. Magnetic stirrer 
was used to float the zeolite. A laboratory flow meter was used for the oxygen flow, which was maintained at $401 . \mathrm{h}^{-1}$. A Lifetech ozone generator with maximum ozone production of $5 \mathrm{~g}$ per hour (value set by the manufacturer) was used for ozone generation. The oxygen and ozone mixture inlet was through a porous frit at the bottom of the reactor. Unused ozone was taken to the destruction column filled with $10 \mathrm{~g} \mathrm{l}^{-1} \mathrm{KI}$.

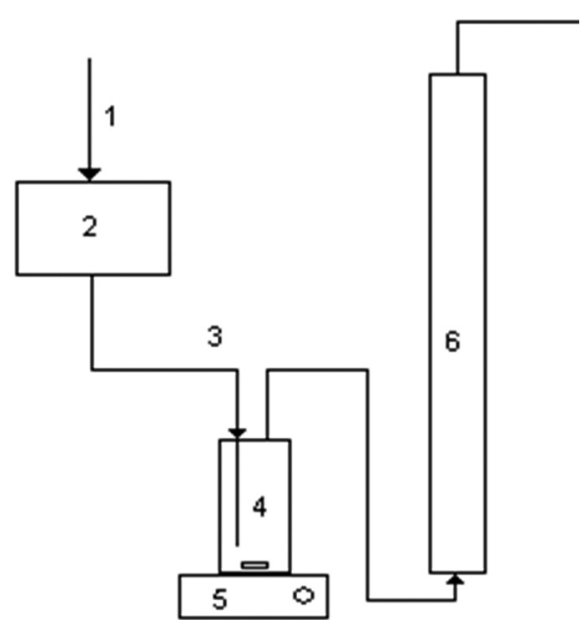

Fig. 1. Laboratory ozonation reactor. 1 - oxygen intake, 2 - ozone generator,

3 - oxygen and ozone mixture, $4-$ stirred ozonation reactor, 5 - magnetic stirrer, $6-$ unused ozone destruction column filled with KI.

Benzothiazole was purchased from Merck. Model wastewater with the $\mathrm{BT}$ concentration approximately $200 \mathrm{mg} . \mathrm{l}^{-1}$ was prepared. Concentrations of monitored substances in synthetic wastewater were measured prior to each experiment.

Reversed-phase high-performance liquid chromatography (RP-HPLC) - HPLC 1090, was used to separate benzothiazole and its derivates. A UV detector with diode array was used for the detection allowing quantification within the UV spectrum and identification of substances in the UV-VIS spectra. A Shimadzu TOC-V $\mathrm{V}_{\mathrm{CPH} / \mathrm{CPN}}$ (USA) analyser was used to measure the total organic carbon (TOC). Basic analytical parameters such as $\mathrm{pH}$ and COD (Greenberg et al., 2005, ISO 6060) were also measured in the synthetic wastewater during ozonation.

Experimental data were processed with zero (1), first (2) and second (3) order kinetic models. The following equations were derived for the batch reaction system, assuming constant reaction volume:

$$
\begin{gathered}
S_{t}=S_{0}-k_{0} t \\
S_{t}=S_{0} \exp \left(-k_{1} t\right)
\end{gathered}
$$

$$
S_{t}=\frac{S_{0}}{\left(1+S_{0} k_{2} t\right)}
$$

where $S_{t}\left(\mathrm{~g} \mathrm{~m}^{-3}\right)$ is the concentration of the substance studied at time $t, S_{0}\left(\mathrm{~g} \mathrm{~m}^{-3}\right)$ is the concentration of the substance studied at time $0, k_{0}\left(\mathrm{~g} \mathrm{~m}^{-3} \mathrm{~h}^{-1}\right), k_{1}$ $\left(\mathrm{h}^{-1}\right), k_{2}\left(\mathrm{~g}^{-1} \mathrm{~m}^{3} \mathrm{~h}^{-1}\right)$ are rate constants for zero, first and second order kinetics.

\section{Results and discussion}

Combination of ozonation with heterogeneous adsorbents represents a potential alternative to increase the ozonation efficiency. In the first part of our experiments, the effect of zeolite dose on the ozonation efficiency was verified. The ozone generator was set to $50 \%$ of its maximum power, while the ozonisation time was 30 minutes. It is obvious from Fig. 2 that increasing the dose of zeolite did not result in any positive trend in the BT removal efficiency. BT removal efficiency, though, was higher (by 10 up to $15 \%$ ) with added zeolite than without it.

The influence of ozonation time on the BT removal efficiency was also determined. The ozone generator was set to $50 \%$ of its maximum power during the ozonation and $0.5 \mathrm{~g}$ zeolite dose was used in each experiment. It is obvious from Fig. 3 that the ozonation time positively influenced the BT removal efficiency, which exceeded $95 \%$ after one hour of ozonation. BT decomposition kinetics during the ozonation with added zeolite can be best described by the first order kinetic model with the correlation coefficient $r_{x y}=0.9950$. The first order rate constant value was $4.05 \times 10^{-2} \mathrm{~h}^{-1}$.

Fig. 4 displays the ozonation time impact on COD and DOC which both decreased with increasing ozonation time, though the decrease was not as significant as that of the BT concentration, since the ozone reacts with $\mathrm{BT}$ at the beginning and some intermediates are formed.

The equations below were applied to evaluate oxidable and mineralised organic pollution portions in synthetic wastewater samples:

$$
\begin{gathered}
\alpha C O D_{o x i}=1-\frac{C O D_{t}}{C O D_{0}} \\
\alpha C O D_{\text {miner }}=1-\frac{D O C_{t}}{D O C_{0}} \\
\alpha C O D_{\text {parcoxi }}=\alpha C O D_{\text {oxi }}-\alpha C O D_{\text {miner }}
\end{gathered}
$$

where $\alpha C O D_{\text {oxi }}$ represents the portion of oxidised $\mathrm{COD}, \alpha C O D_{\text {miner }}$ represents the mineralised COD 


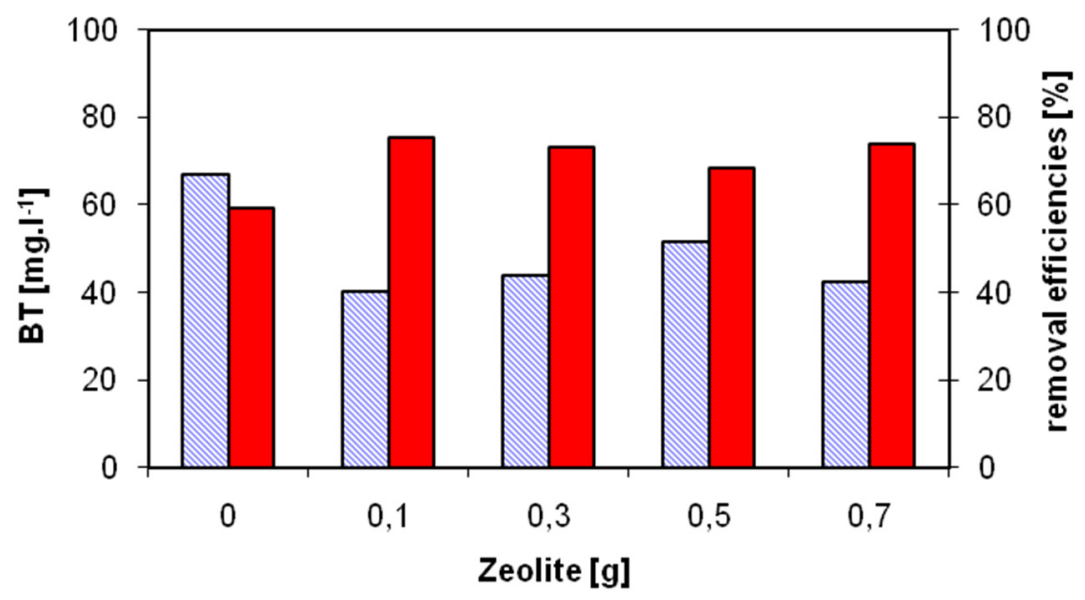

Fig. 2. Zeolite dose impact on BT removal efficiency $\square$ and concentration of BT $\mathbf{~}$ in combined O3/ZEO process.

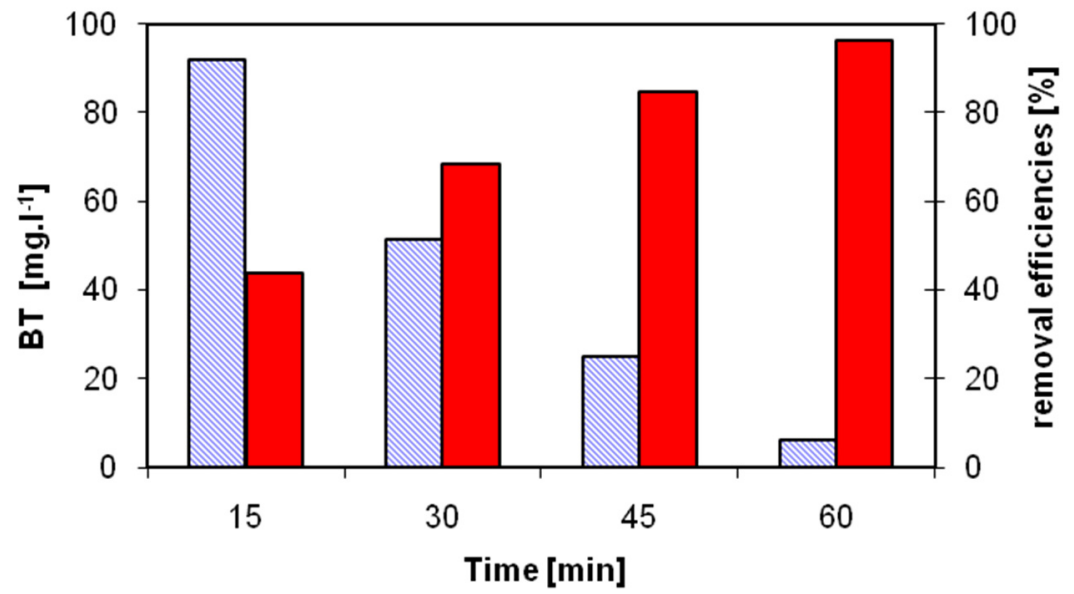

Fig. 3. Ozonation time impact on BT removal efficiency and concentration of BT in combined O3/ZEO process.

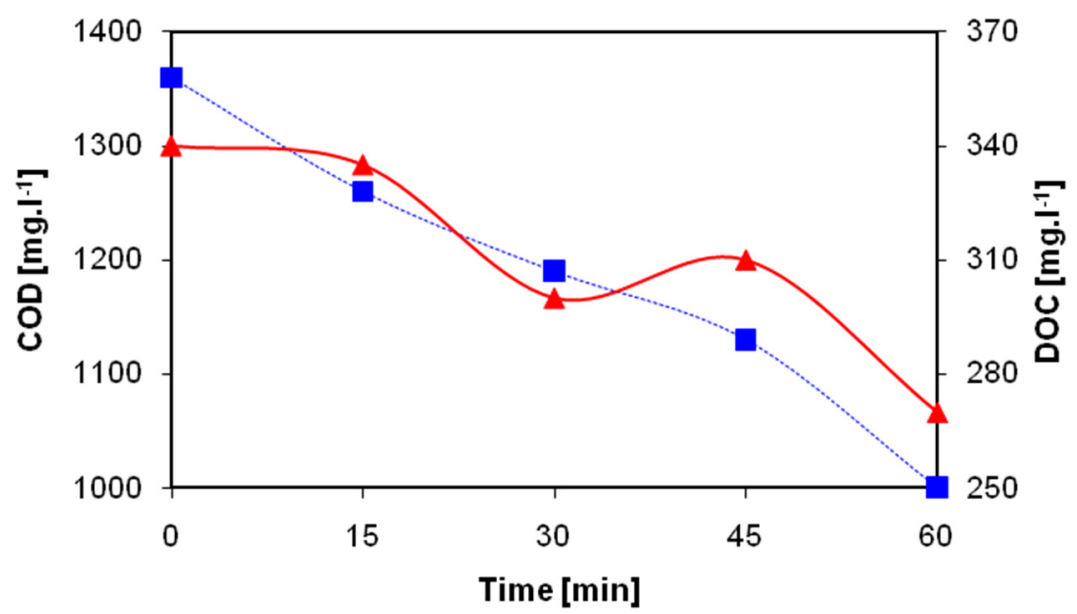

Fig. 4. Ozonation time impact on COD $\square$ and DOC $\Delta$ concentrations.

portion, and $\alpha C O D_{\text {paroxi }}$ stands for the partially oxidised COD. Fig. 5 illustrates the time dependencies of individual COD portions. Most COD was partially oxidised ( $80 \%$ in the $15^{\text {th }}$ minute), during the first 15 minutes of ozonation. The longer the ozonation time, the higher the mineralised COD portion; $78 \%$ of overall oxidised COD was mineralised after 60 minutes of ozonation.

Fig. 6 shows the ozone generator impact on the BT removal efficiency. Ozonation time was 30 minutes 


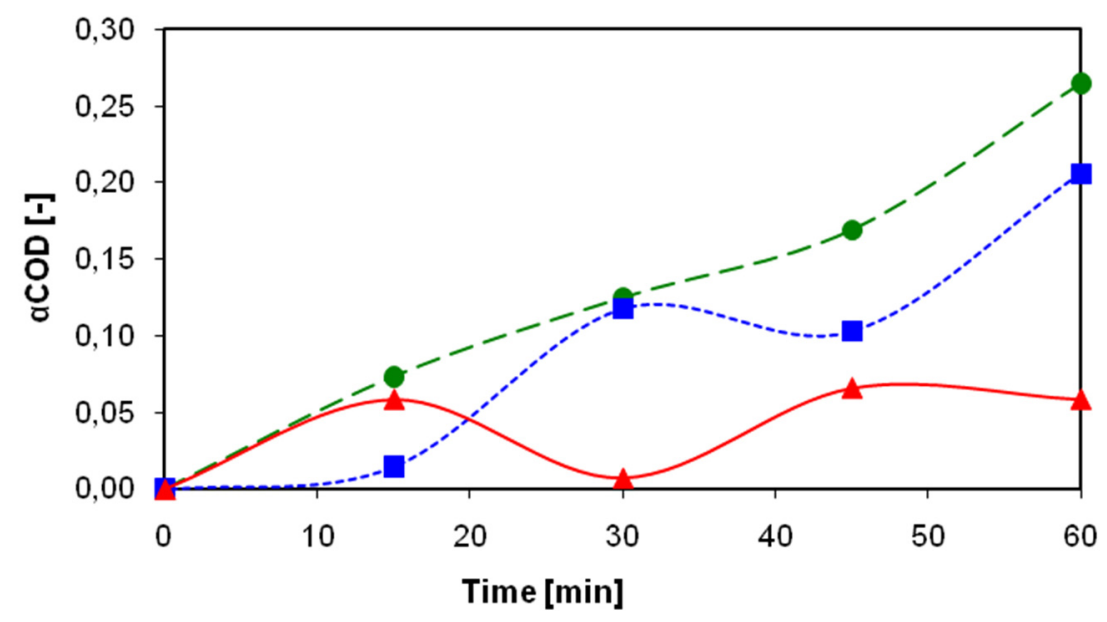

Fig. 5. Time dependencies of individual COD portions:

$$
a C O D_{\text {oxi }} \bullet, a C O D_{\text {miner }} \mathbf{\square}, a C O D_{\text {parcoxi }} \boldsymbol{\Lambda} \text {. }
$$

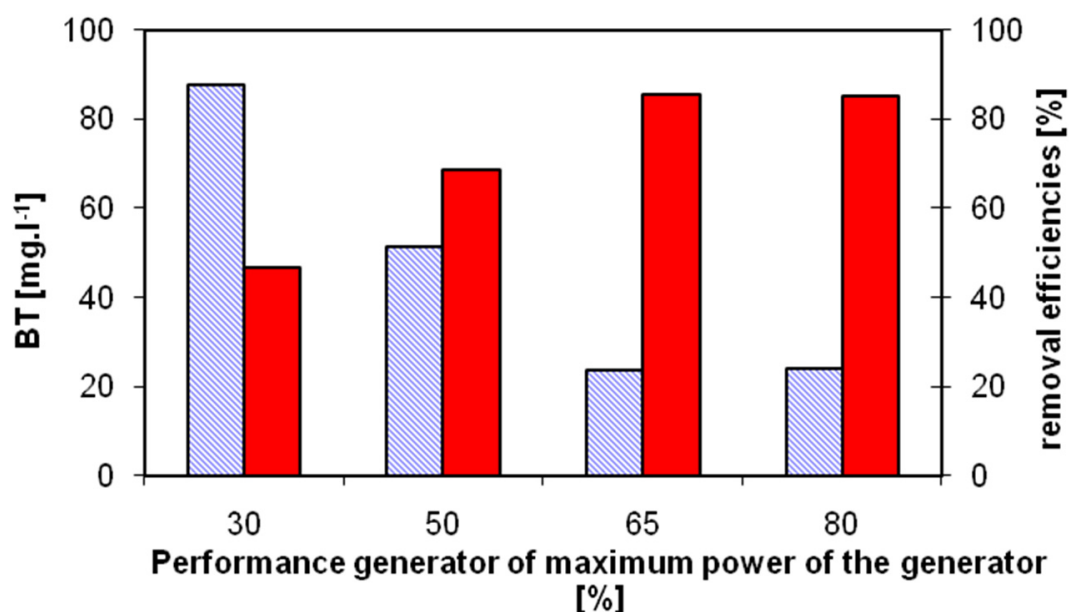

Fig. 6. Ozone generator impact on BT removal efficiency and concentration of $\mathrm{BT}$

in these experiments and the zeolite dose was $0.5 \mathrm{~g}$. An increase in the ozone generator power increased also the BT removal efficiency until the generator reached $65 \%$ of its maximum power. A further increase of the generator power did not result in further increase in the BT removal efficiency. The BT removal efficiency decrease was probably caused by the short ozone retention time in the reactor. A larger volume of generated ozone did not have time to dissolve in the reaction volume. Avoiding discharge of relevant substances into the water ecosystem is the simplest and most economical way to protect water resources. The best way to remove these substances is a municipal or industrial WWTP.

Unfortunately, these cannot be decomposed biologically and thus alternative methods need to be used. Ozonation or combined ozonation, e.g. adsorptive ozonation, is one of the options for pre-treatment of wastewater containing the relevant substances.
Increased BT removal was observed using ozonation combined with zeolite $\left(\mathrm{O}_{3} / \mathrm{ZEO}\right.$ process $)$, from 10 up to $15 \%$ compared to ozonation alone. No correlation between the increasing zeolite dose and the BT removal efficiency was observed. Longer ozonation time positively influenced the BT decomposition efficiency. The highest BT removal efficiency (95\%) was measured after 60 minutes of ozonation. BT oxidation can be best described by the first order kinetic model with $\mathrm{k}_{1}=4.05 \times 10^{-2} \mathrm{~h}^{-1}$ and $\mathrm{r}_{\mathrm{xy}}=0.9950$. Prolongation of the ozonation time increased the mineralised portion in the mixture. Increasing the ozone generation power up to $65 \%$ of its maximum performance resulted in increased $\mathrm{BT}$ removal efficiency, while no BT removal efficiency increase was observed with a further increase in the ozone generator power.

\section{Acknowledgements}

This work was supported by the Slovak Research and Development Agency under the contract No. APVV-0656- 
12.The authors want to thank also for the support from the VEGA Grant 1/0859/14. This contribution is also the result of the project implementation Centre of Excellence of Integrated Flood Protection of Territory ITMS 26240120004 supported by the Research and Development Operational Programme Funded by the ERDF.

\section{References}

Fujita H, Izumi Y, Sagehashi M, Fuji T, Sakoda A (2004) Adsorption and decomposition of water-dissolved ozone on high silica zeolites. Wat. Res. 38: 159-165.

Chudoba J, Tuček F, Zeis K (1977) Biochemister Abbau von Benythiazolderivaten. Acta Hydrochchim. Hydrobiolol. 4(4): 494-498.

Gold L, Slone T, Stern B, Bernstein L (1985) Comparison of target organs of carcinegenity for mutagenic and non-mutagenic checals. Mutat. Res. 296: 74-100.

Greenberg AE, Clesceri LS, Eaton A (2005) Eds. Standard Methods for the Examination of Water and Wastewater. $22^{\text {nd }}$ Edition, Washington, DC.

Kloepfer A, Gnirss R, Jekel M, Reemtsma T (2004) Occurrence of benzothizoles in municipal wastewater and their fate in biological tretment. Wat. Sci. 50(5): 203-208.
Valdés H, Murillo FA, Manoli JA, Zahor CA (2008) Heterogeneous catalytic ozonation of benzothiazole aqueous solution promoted by volcanic sand. J. Hazard. Mater. 153: 1036-1042.

Valdes H, Farfán VJ, Manoli JA, Zaror CA (2009) Catalytic ozone aqueous decomposition promoted by natural zeolite and volcanic sand. J. Hazard. Mater. 165: 915-922.

de Wever H, Verachter H (1997) Biodegradation and toxicity of benzothiazoles. Wat. Res. 31(11): 26732684.

Directive 2000/60/EC of 22 December 2000, establishing a framework for Community policy in the field of water policy. Official Journal L 327, 22. 12. 2000, 0001-0073; EUR-Lex - 32000L0060.

Directive 2008/105/EC of the European Parliament and of the Council of 16 December 2008 on environmental quality standards in the field of water policy, amending and subsequently repealing Council Directives 82/176/EEC, 83/513/EEC, 84/156/EEC, 84/491/ EEC, 86/280/EEC and amending Directive 2000/60/ EC of the European Parliament and of the Council. Official Journal L 348 of 24. 12. 2008, 84-97, EURLex - 32008L0105. 